\title{
Genetic Modification and the Public Good
}

\section{Journal Article}

Author(s):

Potrykus, Ingo

Publication date:

2013

Permanent link:

https://doi.org/10.3929/ethz-b-000422638

Rights / license:

Creative Commons Attribution 3.0 Unported

Originally published in:

European Review 21(S1), https://doi.org/10.1017/S1062798713000203 


\title{
Genetic Modification and the Public Good
}

\author{
INGO POTRYKUS \\ Biology Department, Swiss Federal Institute of Technology (ETH), Zurich, \\ Switzerland; Chairman 'Humanitarian Golden Rice Project', www.goldenrice.org, Im \\ Stigler 54, CH-4312 Magden, Switzerland. E-mail: ingo@potrykus.ch
}

Genetic engineering (GMO-technology) offers great opportunities to contribute to the public good by improving public health, e.g. by improving the micro-nutrient status of poor populations, cost effectively and - therefore - sustainably. The prime example for such a project from the public domain for public good is 'Golden Rice' (www.goldenrice. org). There are exclusive public funds involved (from altruistic organizations), no dependence from industry except for in-kind support and help in acquiring free licenses for humanitarian use. There is no financial reward for anyone involved. The only beneficiaries are the poor in developing countries. Theoretically, when considering the arguments of the anti-GMO lobby, this is an ideal application of GMO-technology. However, Golden Rice is considered a Trojan Horse, which must be prevented under all circumstances. The consequence: millions of avoidable blind and dead children. The author considers those who are responsible for this avoidable suffering of many innocent children (and mothers at childbirth) a crime to humanity. There are those who commit this deliberately and those who are participating passively, such as numerous 'humanitarian organizations' and 'decision makers' in politics and elsewhere. There is a wealth of scientific information and broad consensus that GMO-technology is at least as safe as any other technology involved in any context with our food or our environment. What we experience here is an example of 'unreason' and a perfect example in the context of The March of Unreason. Our 'enlightenment' and sciencebased successful European culture is on the verge of being replaced by unreason-based failure and lack of culture.

Rather than looking at the whole sorry history of the effects of Unreason upon progress in transgenic technology, I will focus on one case, that of Golden Rice. This, I believe, illustrates perfectly how a technology that could save the lives of millions of poor children in Africa and Asia has been blocked by superstition and unreason emanating from the rich West.

For Golden Rice, proof-of-concept was established between 1990 and 1999 in my laboratory in Zurich. Despite this, onerous regulations forbid the roll-out of this lifesaving technology where it is most needed. 


\section{What is 'Golden Rice'?}

Golden Rice ${ }^{1}$ is a 'biofortified' crop providing provitamin A (carotenoids) in the starchy tissue of the endosperm (the part of the rice plant we actually eat). It is yellow instead of white because of the presence of provitamin A, which normal rice endosperm entirely lacks (Figure 1). Golden Rice could not have been developed without genetic engineering technology.

Golden Rice was developed with the intention to contribute to a reduction in Vitamin A deficiency among poor people in developing countries, for which rice, being the staple crop, often is the major cause.

Natural rice is a good source of calories, but it is poor in vitamins and minerals. Provitamin A is totally absent. The consequence is, therefore, vitamin A deficiency. This is a major public health problem affecting around 400 million people (around $6 \%$ of the global population), causing severe medical consequences such as irreversible blindness in half a million children every year. In addition, about two million people die from infectious diseases, which would not be fatal if their diet contained sufficient Vitamin A.

So how can you improve on what nature has provided? We had four alternative routes to 'biofortification'. First, we could use natural variations in the global rice gene pool for traditional breeding. This failed because of a lack of variation.

Secondly, we could use mutagenesis to induce useful variation. This failed as well. A third approach considered was to activate the 'switch' that had turned off the biochemical pathway in the endosperm (rice plants are saturated with provitamin A in all green tissues and, therefore, have all the necessary genes). This has been the subject of an ongoing research programme since 1991, with little success so far.

Finally, we had the option of using transgenic technology. This approach was originally considered to be unfeasible, because it involved eight genes and a total lack of basic knowledge about the necessary cellular basis for expression and storage. However, we were fortunate and discovered that it is possible to engineer the biochemical pathway such that rice endosperm provides - in Golden Rice - so much proviamin A that a daily diet of $40 \mathrm{~g}$ uncooked (150 g cooked) rice is sufficient to completely prevent vitamin A

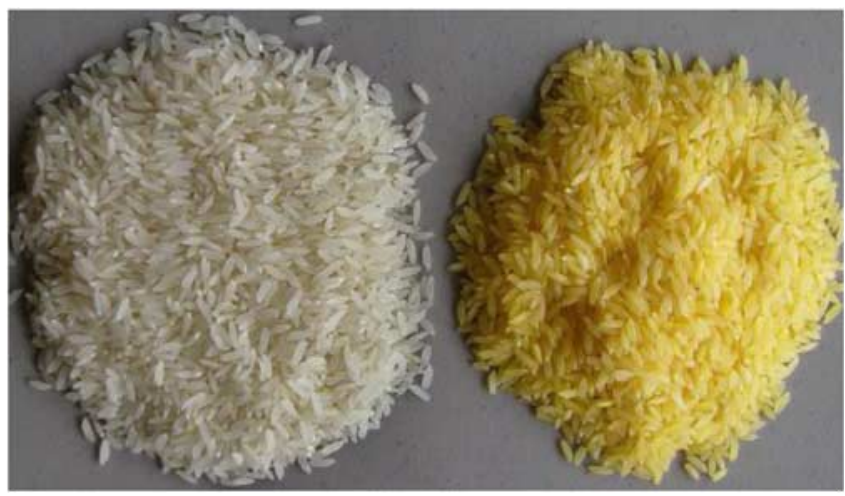

Figure 1. Golden Rice (right) and normal rice. The yellow colour is the consequence of the presence of provitamin A (carotenoids). 


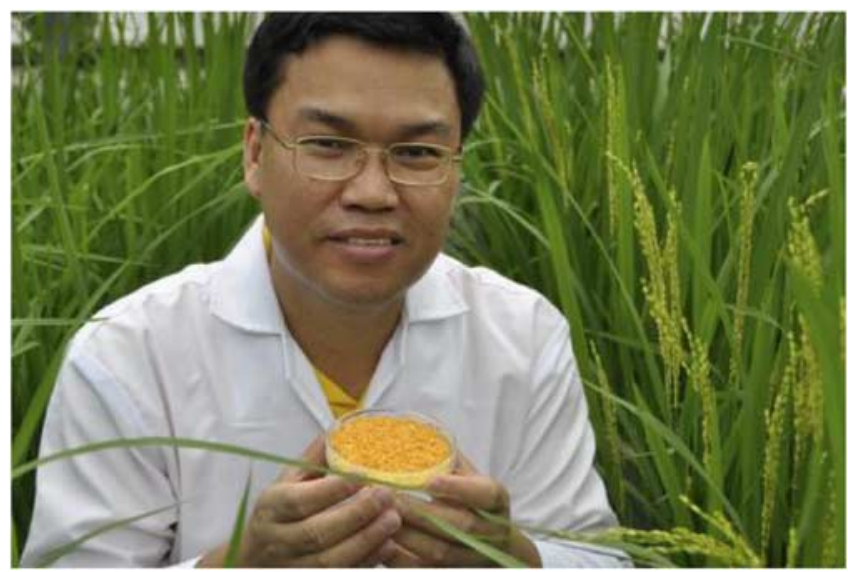

Figure 2. Forty grams of Golden Rice per day (the amount in this dish) can prevent blindness and death for vitamin A-deficient, rice-dependent poor populations.

deficiency and all the associated health problems (Figure 2). In most Developing countries in which rice forms the staple food, children routinely eat $300 \mathrm{~g}$, women $400 \mathrm{~g}$.

\section{How Will Golden Rice Reduce Vitamin A deficiency? How Will it Reach the Needy? Why is it Not Yet in the Hands of the Farmers?}

Bangladesh forms an excellent and representative case-study for Golden Rice intervention. Vitamin A deficiency is a severe public health problem; poor populations depend upon rice as their major food source (up to $80 \%$ of the food calories come from rice). On the basis of their poor diet of rice few women and children reach the critical level of $50 \%$ of the WHO-recommended daily intake, essential for the prevention of vitamin A deficiency related health problems.

A change from normal to 'Golden' rice, even with moderate levels of provitamin A, will provide so much vitamin A (the human body converts provitamin A into vitamin A, the conversion rate from Golden Rice endosperm being an impressive 2:1) that it lifts both women and children across the critical borderline (Figure 3). And Golden Rice will be no more expensive to buy or grow than the normal rice varieties.

The plan is to make Golden Rice available to subsistence farmers free of charge. Farmers will be able to use the seeds in the traditional way, with no additional agronomic inputs, such as pesticides or herbicides, required. Vitally, they will be able to use part of the harvest as seed for the next sowing. We predict that yields will be at least as good as from traditional varieties and the rice tastes exactly the same as non-transgenic varieties.

The only caveat is that this 'humanitarian' use is free for farmers whose income is below US $\$ 10,000$ per annum, but local trade is permitted. Importantly, the technology is 'in the seed' and is covered by free licences to all technology involved.

Golden Rice has been a scientific reality since February 1999. Even before that we had established collaboration with the International Rice Research Institute (IRRI) in the 


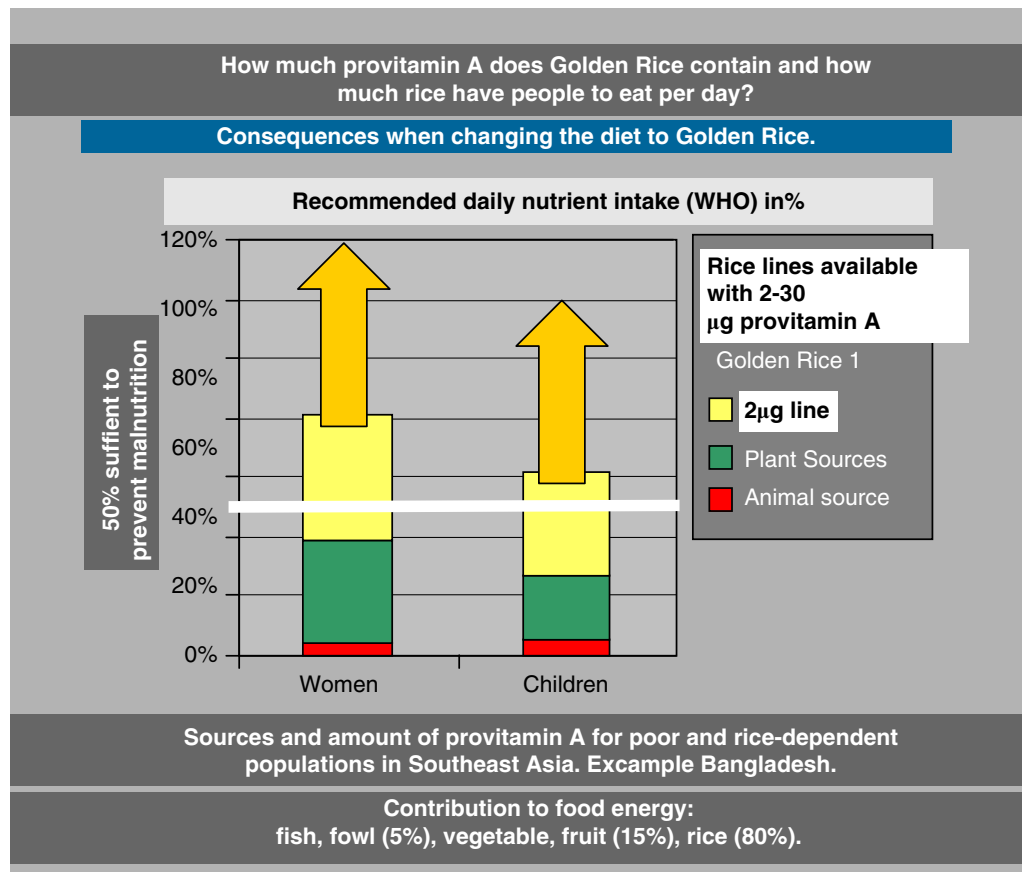

Figure 3. The nutritional situation in Bangladesh.

Philippines for development and release. According to IRRI rice breeders, release would have been possible from 2002 onwards.

But despite the intensive work put in by us and our numerous partners, and despite receiving generous financial support from altruistic organizations and support from some governments, Golden Rice will not reach the farmers in the Philippines before the end of 2013, followed by those in Bangladesh in 2014, India and Vietnam 2015, and China and Indonesia 2016. This delay in deployment - an estimated 12 years over the delay for release of a conventional new rice variety - is solely due to the conditions for work with transgenic plants and the requirements for deregulation (Figure 4).

\section{How did Regulation Delay Deployment of Golden Rice?}

If it was not a GMO, the trait 'provitamin A in the endosperm' would have been introgressed (by repeated backcrossing to dilute the donor genome) into rice varieties consumed by the target population. To replace more than $95 \%$ of the donor genome takes eight backcross generations without and only half of that with 'marker-assisted' breeding, directly applicable to the 'Golden' trait. Within three years the rice breeders at IRRI would have done the job.

Golden Rice had to follow the numerous rules and regulations set up as law worldwide for work with transgenic plants. These rules and regulations concern partly the molecular characterization of the genome, partly the biochemistry, expression profiling, compositional and phenotypical analysis and in part and environmental risk assessment. 


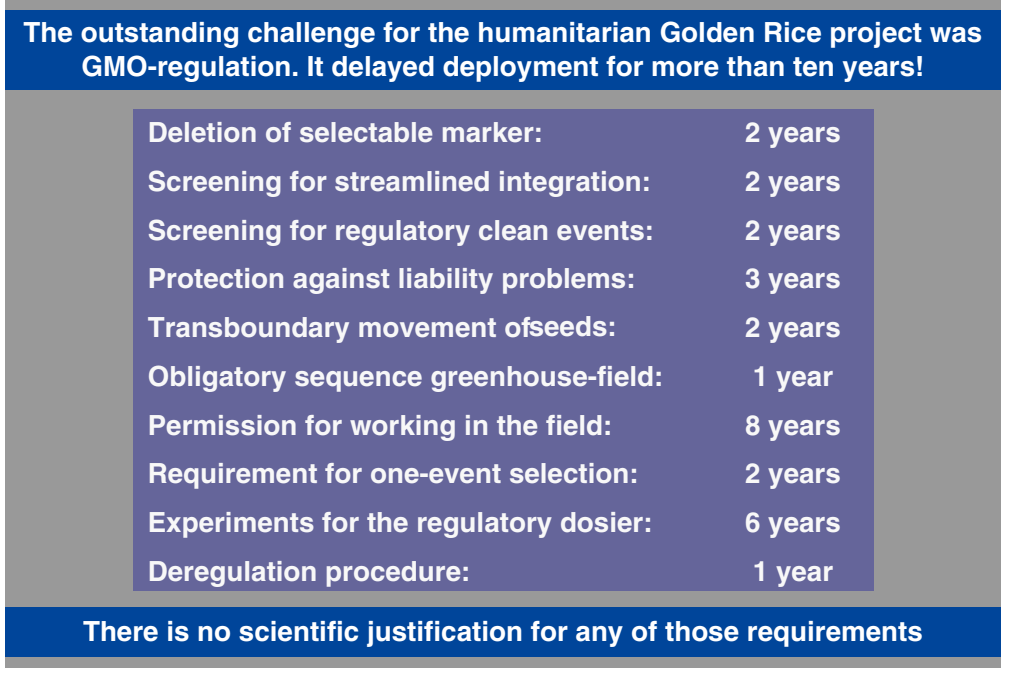

Figure 4. The table indicates how the deployment of Golden Rice has been delayed, and by which regulatory authorities. Allowing for the fact that some work could be done in parallel, the overall delay was at least a decade.

All this has to be done under very restrictive experimental conditions. Whereas plant breeders can work with large samples grown in the field (important for both the numbers and the response to the environment), GMO-breeders have to work in small growth chambers and under artificial environments.

Regulatory authorities worldwide do not tolerate antibiotic resistance genes as used for selection of successful transformation, although there is sufficient literature that shows that there is no risk from those in use. It took more than two years to breed the resistance gene out. Later on we shifted to selection based on a sugar alcohol, which gives that company which patented this technology, a monopoly for 'acceptable' transformation.

In addition, the regulatory authorities do not accept any transgenic alteration that involves more than the absolute minimum of 'foreign' DNA integrated in a single copy and without any rearrangement. This cannot be achieved deliberately and requires repetition of the same experiment, with regulation adjusted vector molecules, until such an event shows up by chance. This took hundreds of repetitions and more than 4 years.

Regulatory authorities typically give permission for field testing only after experimental data collected in growth chambers and glasshouses provide evidence that there is no possible environmental risk. It wasn't until 2008 that we finally received permission for a small field trial in The Philippines.

The 'Humanitarian Golden Rice Network' spans over six countries and the breeders involved are supposed to collaborate and exchange breeding material. Because of the bureaucracy as a consequence of the Cartagena Protocol, which controls transboundary movement of plant material and considers a priori GMO seed as highly risky; it took more than 2 years before we were allowed to take seeds out of the experimental areas. 
Deregulation (permission to use a transgenic plant) is based on transgenic events (the specific molecular situation of a specific case). Because of the costs of deregulation (c.\$20 million per event), it is mandatory to develop multiple varieties via traditional breeding from one single event - the 'lead event', because all varieties derived via traditional breeding from one 'event' are, from the regulatory point of view, considered one event. All variety development in all countries follows, therefore, the strategy of using traditional breeding from one 'event' to produce numerous novel varieties. This minimizes the costs substantially. To decide for the 'lead event' amongst numerous others requires, however, a host of molecular, biochemical, and agronomic data from all these events to be considered, to allow for rational decision. Only after 8 years of work were we in the position to identify the 'lead event'.

There are further GMO-specific hurdles, which I will not discuss in this context. There is, however, an important message: there is zero scientific justification for any of these requirements.

\section{What are the Consequences of this Delay in Deployment for more than Ten Years?}

Studies ${ }^{2}$ have shown that Golden Rice could save, in India, c40,000 lives a year and prevent blindness in tens of thousands of people (Figure 5). Extrapolated to all those countries, where Golden Rice is under development, the number of deaths we could prevent far exceeds 100,000 a year. Considering the delay of 10 years, it is justifiable to state that GMOregulation is responsible for the deaths of more than one million people, mostly children and pregnant women. And this figure represents only one single case, Golden Rice.

As there are many other cases of transgenic technology that have a high potential for improving both the yield and nutritional quality of staple crops, the overall cost of overzealous GMO-regulation is probably in the range of tens of millions of deaths.

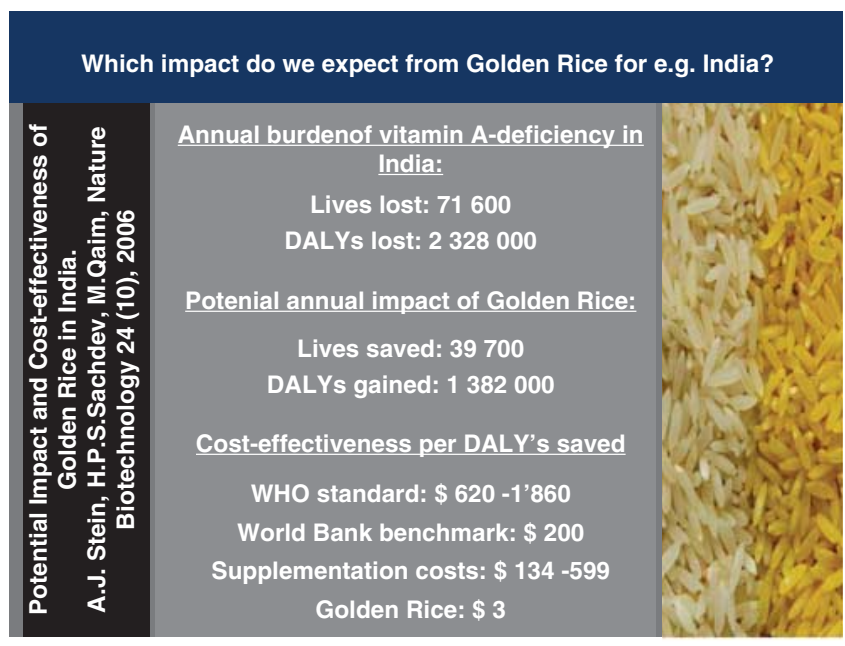

Figure 5. Ex-ante impact studies have shown that Golden Rice interventions would be effective, economic, and sustainable. 
Considering the human and social consequences of so many deaths (and blindness), there must be an overwhelming reason for GMO-regulation to balance this humanitarian and social catastrophe.

\section{What Then is the Stated Justification for this GMO Regulation?}

There is one key argument: the technology leads to 'uncontrolled and unpredictable alterations of the genome' and therefore to unpredictable risks to the consumer and the environment. This is true in so far that the integration of the incoming DNA is random (uncontrolled) and can inactivate or activate host genes (unpredictably), leading, possibly, to unexpected changes in gene expression and phenotype. This is not new. Plant breeding has always worked, and is still working, on that basis, and all crop plants in use are the result of long histories of 'uncontrolled and unpredictable alterations of the genome' - they all are most intensively 'genetically modified'. This is illustrated with the breeding history - the 'breeding tree' - of the most successful Indica rice variety IR64 compared with that of Golden IR64 (Figure 6).

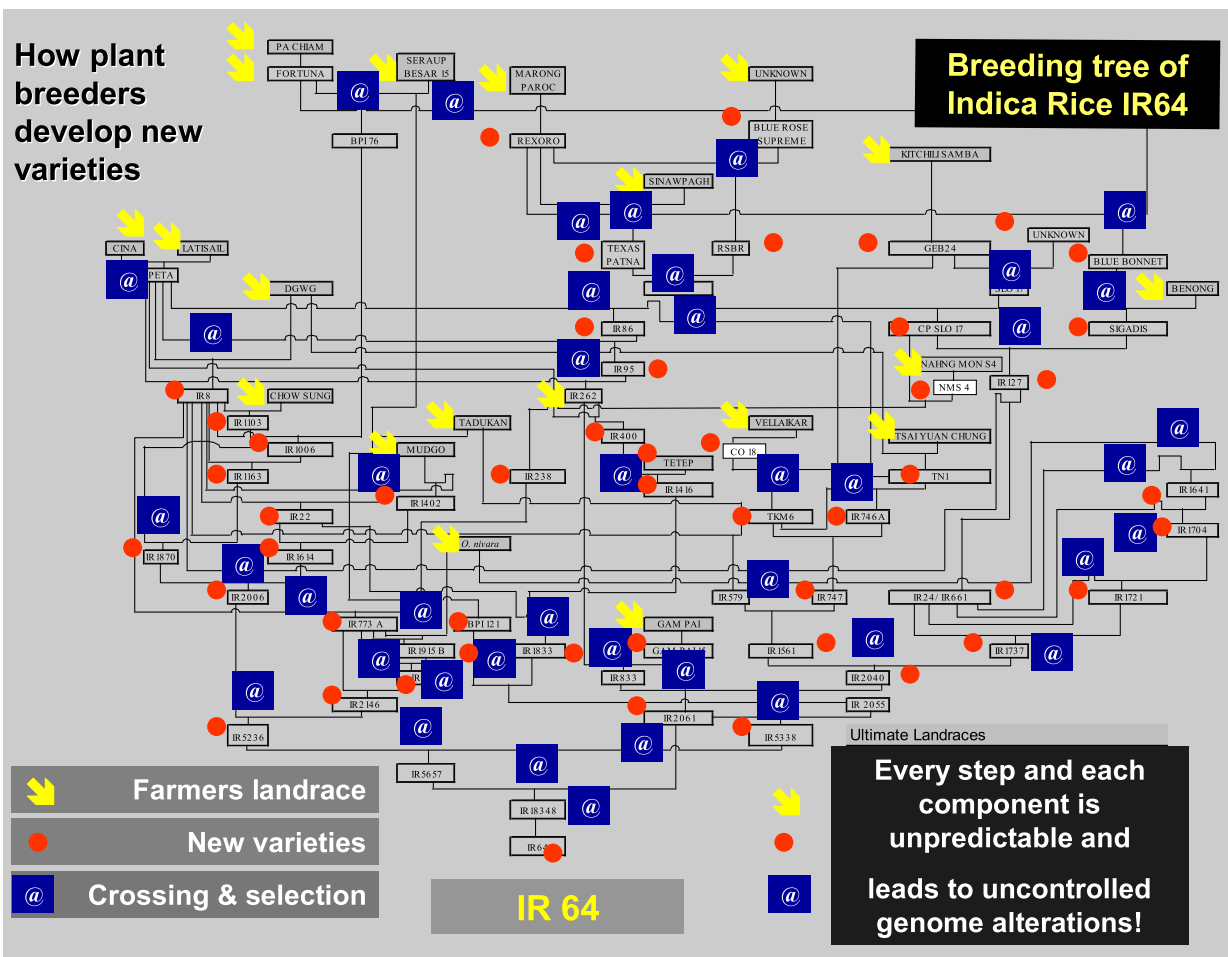

Figure 6. The history of the most successful rice variety IR64 reads from top to bottom. The yellow arrow heads represent 'landraces' developed by farmers and characterized by undefined 'mutations'. The red dots are new varieties developed over time by professional breeders. The blue boxes depict the breeding process - crossing and subsequent selection. All this leads automatically to an accumulation of 'uncontrolled and unpredictable genetic modifications', as illustrated in Figure 7. 


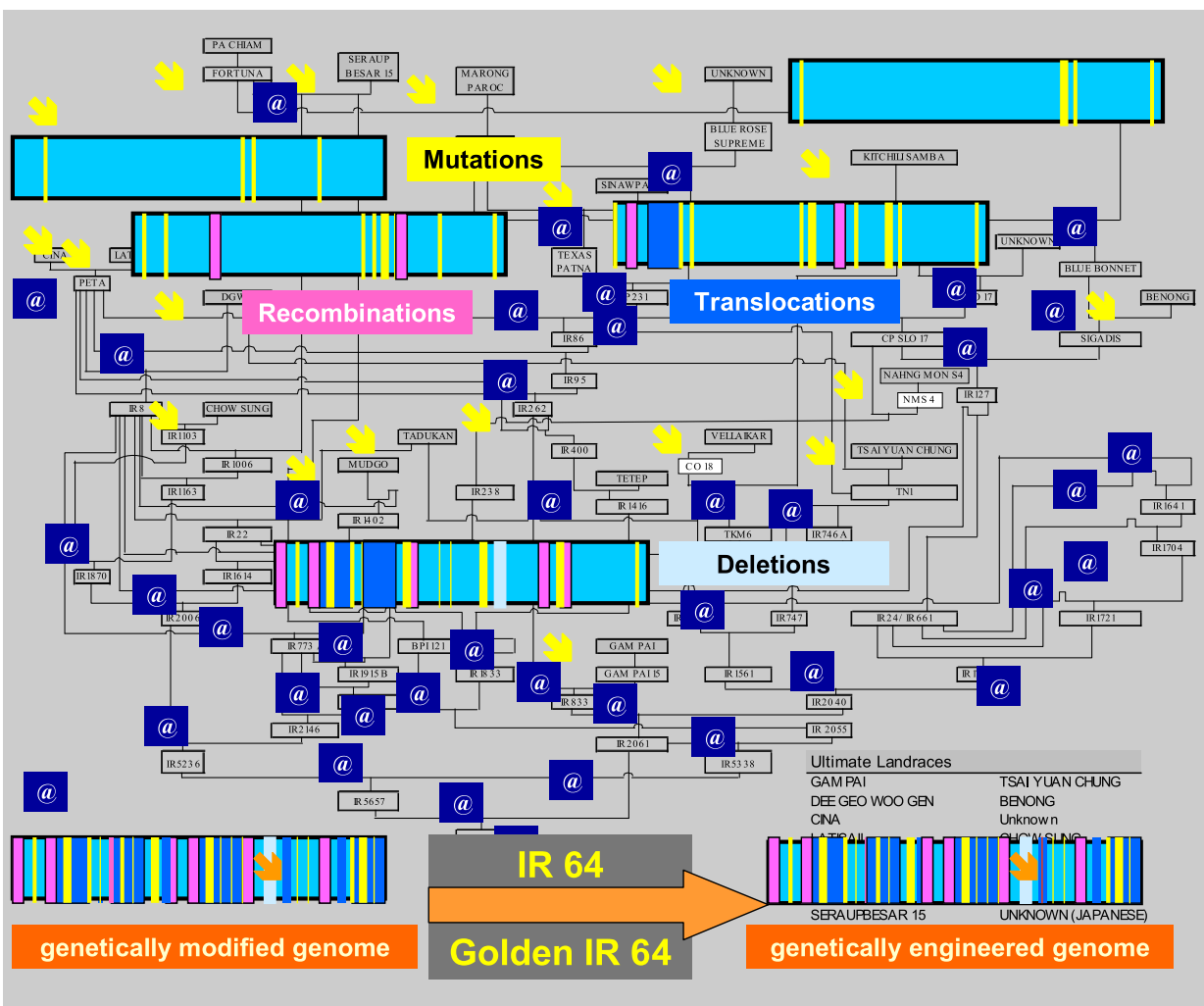

Figure 7. The situation with regards to the genetic modifications for non-GM IR64 and for GM-Golden IR64.

In contrast, Figure 7 shows the situation with regards to the genetic modifications for non-GM IR64 and for GM-Golden IR64 - or, similar, for any other GMO-based variety. Coloured bars represent 'genetic modifications' - mutations, translocations, inversions, recombinations, deletions and so on.

These are all a consequence of the traditional breeding process and have nothing to do with genetic engineering. All these modifications are 'uncontrolled and unpredictable' and they are accepted without any regulation. As it will not be easy to see the tiny difference of the additional genetic modification as the consequence of the genetic engineering process, this has been marked by an orange arrow head.

This additional minimal and extremely well-studied modification triggers, however, the regulation as described above, with all its consequences (including the deaths of millions). We have accepted all 'traditional' highly genetically modified crop plants without any regulation, on the basis of 'trial and experience' and there is no rational argument not to continue on these lines. There is one additional argument used to defend GMO-specific regulation: transgenes can be taken from outside the natural species border. (Golden Rice contains a gene from a soil bacterium - which we eat daily on our salad).

This argument is false because there are no species-specific genes. Genes are neutral pieces of information, linked across any 'artificial' systematic border, via evolution. 
The fact that the gene from the soil bacterium functions without any problem in rice is an illustration of the genetic continuum of our life world.

There is now a scientific consensus that transgenic plants (and genetically engineered organisms in general) do not deserve special regulation.

For instance, the Organization for Economic Co-operation and Development (OECD) has published guidelines entitled: 'Recombinant Safety Considerations' in which it is stated: " "There is no scientific basis for specific legislation to regulate the use of recombinant DNA organisms., ${ }^{3}$

This is followed by numerous publications from national and international academies, the last publication coming from the Pontifical Academy of Sciences, ${ }^{4}$ which confirms that specific regulation of GMO-technology has no scientific justification, that regulation should consider the 'trait' (e.g. provitamin A) and not the technology used to acquire the trait.

The Pontifical Academy of Sciences adds a novel aspect to the debate by stating that there is a "moral imperative to make the benefits of the technology available on a larger scale to the poor and vulnerable populations who want them and on terms that will enable them to raise their standards of living, improve their health and protect their environments.'

\section{What Should we have Learned? What Did we Learn?}

We know that there is no GMO-specific risk to human health or to the environment. Specifically, we now know from 25 years of biosafety research that there has been no GMO-specific risk and that there has not been a single documented case of harm to either consumer or the environment.

All this is widely published and documented, but the public, the politicians, the media, the professional and self-styled ethicists, and the regulatory authorities ignore this scientific consensus and do not change their position. For them, transgenic plants are inherently unpredictable, dangerous and require strict control. It would be best to ban them. Instead of liberalizing regulations in response to increasing knowledge, regulation is applied with increasing rigour. The 'Humanitarian Golden Rice' project had to follow all established rules with all the negative social consequences given above.

\section{Why is it so Difficult for the Public to Follow Science and Reason?}

It is understandable that laymen (including ethicists and journalists) cannot critically judge scientific and technologic novelty. But why do they not trust scientists, especially the academies that are neutral as opposed to various industrial interests that may be biased by profit motives?

Why is it that activists who have a demonstrated self-interest and lack scientific qualification, enjoy so much credibility, despite the fact that their numerous claims for damage from transgenic plants have been falsified by rigorous scientific studies?

As stated above: there is not a single documented case of harm that would have survived scientific falsification. There is a simple but effective strategy anti-NGO activists have been applying to transgenic plants for decades: (1) claim a harm (which takes seconds); (b) enjoy how science works hard for years to prove that the claim was 
unsubstantiated; (c) enjoy even more how nobody is interested in the falsification of the claim. As I learned from an activist: 'the most important feature of news is, to be first'.

\section{Campaigning against GMOs has become a Lucrative Business}

The anti-GMO movement has established an effective feedback circle of support: 'Green' departments of national and supra-national governments finance environmentalist 'NGOs" with the political objectives of these departments. This is all legal, justified with the argument that the lobbying of industry must be balanced by support for lobbying by 'independent' groups of civil society.

This mechanism ensures that the public has the impression that the governments are working in the interest of the public. The public does not realize that financial support for NGOs is coming from the government, and is assuming that NGOs have no self-interest and are honest brokers of public interest. However, the yearly budget available for NGO-campaigning is in the range of more than $€ 2$ billion, not only coming from governments but also from donations and from industry, with the organic food industry being one of the most generous supporters.

Despite this, common wisdom has it that it is the agri-biotech industry that is the financial giant, influencing the public in favour of GMOs and that NGOs are the Davids fighting against these giants. I have no detailed information how much money goes into pro-GMO campaigns from industry, but it is obvious that it can amount to only a small fraction of what is flowing into anti-GMO campaigns.

\section{The Damage to Life and Welfare is Astronomic}

According to Patrick Moore, co-founder and long year president of Greenpeace, the motivation behind much of the campaigning is anti-corporate, anti-globalization, antiscience and deeply political. 'Green language' is used effectively to this end. Those who suffer most in this political fight are not so much the corporates (the prime devil being Monsanto) but those hundreds of millions of poor who suffer from food insecurity and have no lobby.

Corporate exploitation of GMO technology is flourishing, yet the use of the technology for the public good (feeding the poor with cheap and nutritious food at minimal environmental cost) has no future in the political climate created by those who pretend to campaign in the interest of the underprivileged and the environment.

At the end of the nineteenth century, a Thai princess celebrated her 18th birthday close to a lake in the palace gardens (Figure 8). She fell into the water and drowned despite hundreds of guests surrounding the pool. Nobody helped her out of the water because it was taboo to touch a member of the royal family. We have no truck with ridiculous taboos today, or so we think. However, in the early twenty-first century, half a million children per year are losing their sight and 2 million are dying because of vitamin Adeficiency. Much of this misery could be prevented by the deployment of Golden Rice. However, our 'enlightened' societies insist on considering GMOs as strictly taboo despite overwhelmingly powerful scientific arguments in favour of their use. If our 


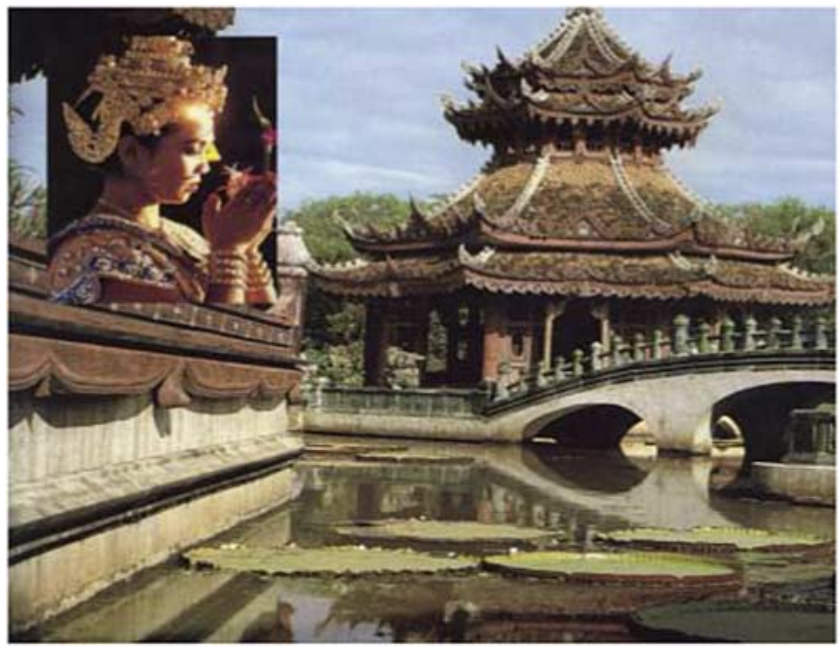

Figure 8. The taboo not to touch a member of the royal family killed a princess in the nineteenth century.

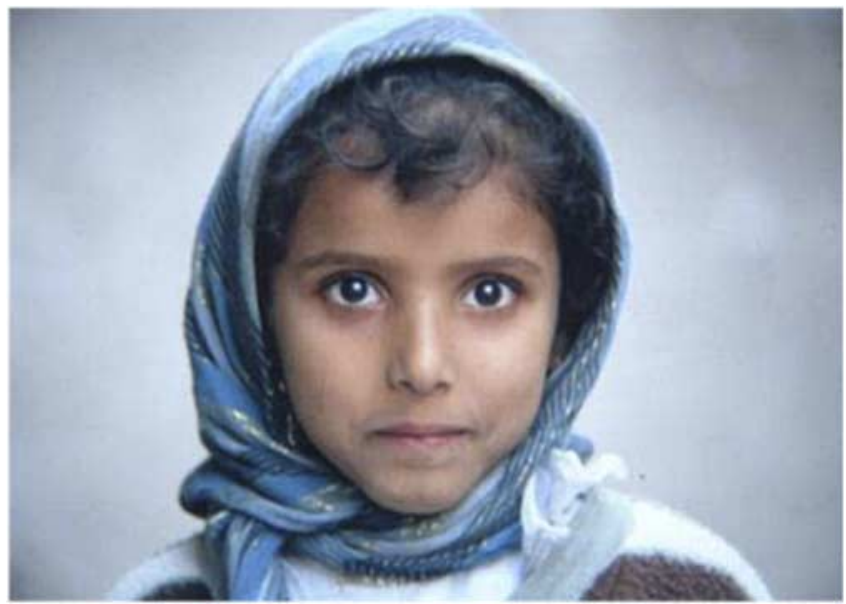

Figure 9. I accuse those of a 'crime to humanity' who killed my sister and blinded my brother, by delaying or even preventing deployment of health- and life-saving technology such as Golden Rice.

society will not be able to 'de-demonize' transgenic technology soon, history will hold it responsible for the death and suffering of millions of people in the poor world, not in overfed and privileged Europe, the home of the anti-GMO hysteria (Figure 9).

\section{References}

1. Humanitarian Golden Rice Board, Homepage. www.goldenrice.org.

2. A. J. Stein, J. V. Meenakshi and M. Qaim (2008) Genetic engineering for the poor: golden rice and public health in India. World Development, 36, pp. 144-158. 
3. OECD (1986) Available at: www.oecd.org/dataoecd/32/15/37623706.ppt.

4. I. Potrykus and K. Ammann (2010) Transgenic plants for food security in the context of development. NewBiotechnology, 27(5), pp. 443-715; Executive Summary, 645-656.

5. A. Apel (2008) Europe's funding of world-wide activism. http://www.gmobelus. com/2008/08/24/europpes-funding-of-worldwide-activism/printer

\section{Further Reading}

A. Apel (2010) The costly benefits of opposing agricultural biotechnology.

NewBiotechnology, 27(5), 635-640.

P. Beyer (2010) Golden Rice and "Golden crops for human nutrition.

NewBiotechnology, 27(5), 478-481.

B. M. Chassy (2010) Food safety risks and consumer health. NewBiotechnology, 27(5), 534-551.

H. I. Miller (2010) The regulation of agricultural biotechnology: science shows a better way. NewBiotechnology, 27(5), 628-634.

I. Potrykus (2010) Constraints to biotechnology introduction for poverty alleviation. NewBiotechnology, 27(5), 447-448.

I. Potrykus (2010) Lessons from the 'Humanitarian Golden Rice' project: regulation prevents development of public good genetically engineered crop products.

NewBiotechnology, 27(5), pp. 466-472.

M. Qaim (2010) Benefits of genetically modofied crops for the poor: household income, nutrition, and health. NewBiotechnology, 27(5), pp. 552-557.

J. von Braun (2010) Food insecurity, hunger and malnutrition: necessary policy and technological changes. NewBiotechnology, 27(5), pp. 449-452.

X. Ye, S. Al-Babili, A. Klöti, J. Zhang, P. Lucca, P. Beyer and I. Potrykus (2000) Engineering provitamin A ( $\beta$-carotene) biosynthetic pathway into (carotenoid-free) rice endosperm. Science, 287, pp. 303-305.

\section{About the Author}

Ingo Potrykus received his $\mathrm{PhD}$ in 1968 for work at the Max Planck Institute for Plant Breeding Research. He joined the Institute of Plant Physiology, Stuttgart, in 1970 where he began his scientific career, with the aim of developing genetic engineering technology for crop plants. In 1974 he continued his work at the Max Planck Institute for Genetics, along the same lines. He was determined to open up important crop plants for the upcoming technology, with the goal of developing and using the technology for the public good. In 1956 he moved to the Friedrich Miescher Institute (FMI) Basel. Plant science at the institute soon put it on the map. In 1986 he accepted a full professorship in Plant Sciences at the ETH Zurich. From then on he could follow his concept. With his partner, Dr Peter Beyer from Freiburg, Germany, and thanks to persistence and good fortune, his best known case, Golden Rice became a scientific reality (for this and the following visit www.goldenrice.org). He retired in March 1999 and established a 'public NGO', an advisory board, and a network of collaborating public rice research institutes. He continues to chair this $\mathrm{NGO}$, with the task of developing a product that can be handed out to the needy in as many countries as possible. According to the timeline, Golden Rice should begin to reach the needy by the end of 2013 (www.irri.org/goldenrice). The only remaining problem is, probably, the anti-GMO lobby. 